\title{
Voting by Quiz: Online Algorithms and Election Education
}

\author{
ERIC B. KENNEDY ${ }^{1}$ \\ Arizona State University
}

\section{Introduction}

On October 19th, 2015, Canadian citizens will head to the polls in their country's 42nd general election. The vote offers the choice between the existing right wing government (Stephen Harper's Conservatives), three largely left-of-center alternatives (the New Democrats, Liberals, and Greens), a regional party (the Bloc Québécois), and several independents and minor parties. At the same time, like in many other countries, Canada is plagued by concerns about voter apathy and lack of participation, especially among younger demographics.

This apathy, however, contrasts with over one million users that have visited and used the Canadian version of the political website iSideWith.com. Even more-over 21 million visitors - have used the American version of the website to help choose which presidential candidate to vote for. ${ }^{2}$ These voting advice applications have a simple premise. Visitors to the site complete a quiz about their views on major election topics, ranking these issues as more or less important to them. At the end of the survey, voters are offered results ranking the parties they "side with," each of which offers an alignment score representing the degree of agreement. Users are encouraged to share their results via social media and encourage others to "turn 10 friends into educated voters." 3 According to Dr. Matthew Wall's article on these applications in the recent UK general election, "Diverse, Popular, and Growing in Importance," the proliferation of such websites has been accompanied by a wide range of methodologies, representations, and calculations. In Canada, other advice websites include the Vote Compass and the Vote Selector

\footnotetext{
${ }^{1}$ Eric B. Kennedy, Email: ericbkennedy@asu.edu

2 As of October 1, 2015, the Canadian version had 1,044,893 users, and the American had 21,351,333, per the counter on the website.

${ }^{3}$ Sidebar ad at https: / / canada.isidewith.com.

Copyright (C) 2015 (Eric B. Kennedy). Licensed under the Creative Commons Attribution Non-commercial No Derivatives (by-nc-nd). Available at estsjournal.org.
} 
Quiz, alongside a number of quiz websites.

For those accustomed to determining their votes via traditional reporting, debates, door visits by canvassers, and electoral speeches, such a technology offers a potentially frightening new influence on today's voters. Yet, electoral websites and online engagement alternatives offer significant potential benefit for engaging and educating at least some voter demographics on many election issues, according to Cheryl Anderson's article "Can Electoral Websites Increase Youth Participation?" Neither excessive skepticism nor uncritical embrace is sufficient. Rather, such websites underscore the importance of accuracy, transparency, nuance, and reflection in any democratic technology.

\section{Accuracy and Iterative Improvement}

iSideWith gained immense popularity in Canada nearly immediately, trending on social networks shortly after the election was called and offering early advice for potential voters. Yet, the reliability of the scores for these early users was questionable. After completing the quiz, users are offered a chance to compare their results with the positions of each political party on up to thirty-eight different questions. On occasion, the website reports that it "could not determine" a given party's position on a particular issue. Results calculated August 7th, for instance, were highly incomplete. Only $61 \%$ of issues had a position listed for the Conservative party, and only $53 \%, 47 \%$, and 38\% for the Greens, New Democrats, and Liberals respectively. Moreover, many of these missing positions surrounded key election issues, including any party's stances on a controversial omnibus anti-terrorism bill, foreign aid or defense spending, free trade deals, and whether corporations should be allowed to donate to political campaigns.

Accuracy, however, is not simply providing correct information about the positions of parties. Ongoing and iterative updates are also essential. To their credit, nearly all of these

missing stances were updated on iSideWith throughout the subsequent week. This delay, however, raises questions about the ethics of launching such a tool prior to completion. If the website is indeed as influential in shaping its users' voting behaviors as its creators hope, a more prudent approach would be to ensure completeness and accuracy prior to public launch. Moreover, while the website's ongoing updates offer a powerful method for tracking beliefs relative to shifting party positions, neither the design nor the text of the website foregrounds the importance of returning to the site regularly to reexamine changing scores. Such a website also problematizes what should count as a legitimate source. For Conservative positions reported on October 1st (just over two weeks before the election and eight weeks into the campaign), for instance, eight of thirty-six determined positions had no citation supporting them. Of those with 
citations, not a single one came from an active Conservative policy document, campaign website, or official publication. Sixteen came from non-party sources (including lobby groups like the Sierra Club, the "World Socialist Web Site," and nine news articles and editorials-not a single of which was published after the writ was dropped, and several of which were between 1-3 years old or dead links); eight offered dead "404 Page Not Found" links to the Conservative website; one linked to their removed 2011 election platform; one linked to their 2004 election platform; one linked to a personal blog; and one linked to a Wikipedia page.

\section{Party Positions and Non-binary Answers}

Perhaps more interesting, however, is the question of what should count as a "party position." A narrow definition might only consider positions that are party of a party's official platform. Such an approach, however, is rarely foolproof. The Green party, for instance, has been adamant in their opposition to Bill C-51 (omnibus anti-terrorism legislation), including documents on their website stating it "should be repealed at the earliest opportunity," despite the issue not appearing in their official "Vision Green" platform several weeks into the campaign.

Broader assessments of platforms could include leader statements, debate positions, or longstanding policies. Yet, the boundaries of this approach are unclear: Should, for instance, repeated attempts by Conservative backbenchers to forward "pro-life" bills count as part of the Conservative stance on the issue-especially since the other parties have explicitly adopted "prochoice" positions-despite the party claiming they do not support these endeavors? Or, in the absence of an official statement, should it be assumed that the Conservatives are opposed to reinstating the mandatory national census they abolished? Should other parties also be assumed to oppose reinstatement unless they have explicitly stated otherwise?

Part of the difficulty in assessing a party's position arises from the scope and framing of the questions. For instance, one question asks whether "the federal government [should] invest in urban, commuter rail infrastructure." The Conservative party is scored as a "yes" based on an April 2011 article by CityMayors.com, in which the Conservative's 2011 election platform promised a "long-term investment in infrastructure." Even if this source featured a current promise to do the same, however, should a commitment to fund some infrastructure programs count as broad support of urban, commuter rail infrastructure? How should concrete funding of particular infrastructure projects be weighed against abstract but broader promises to support rail in general? 


\begin{abstract}
Algorithmic Transparency
Another major challenge stems from blackboxing the algorithm out of sight from users. According to the FAQ alignment scores consider elements like "passion," "confidence," and "priority" of the candidate's stance, as well as elements like their voting record. Yet, little detail is provided about how each of these is determined, or just how similar a "similar" answer must be before it is counted as agreement. Consider the contrast between Figures $1 \& 2$ below-the first of which is scored as a disagreement, the latter as a "similar" agreement. Yet, a human interpretation would suggest that the views in Figure 1 are likely much more agreeable (we agree on the core question, and may or may not disagree on an additional pathway) than in Figure 2 (where, despite both answering yes, the qualifiers are so restrictive that they may be significantly different positions).
\end{abstract}

\begin{tabular}{|c|c|}
\hline $\begin{array}{l}\text { Should the federal government } \\
\text { subsidize the production and } \\
\text { consumption of renewable energy } \\
\text { sources? stats discuss }\end{array}$ & $\begin{array}{l}\text { Somewhat } \\
\text { important }\end{array}$ \\
\hline \multicolumn{2}{|l|}{ New Democratic: Yes } \\
\hline $\begin{array}{l}\text { You: Yes, and also advance the } \\
\text { nuclear plants in Canada. }\end{array}$ & ion of nev \\
\hline
\end{tabular}

Figure 1: An issue scored as "not siding together"

\title{
Should Canada allow the logging of old growth forests? stats discuss Conservative: Yes Your similar answer: Yes, but only selective logging, no clearcutting, and a plan for regrowth
}

Figure 1: An issue scored as "siding together"

More fundamentally, the inclusion of particular topics within the quiz serves to validate their legitimacy as fundamental election issues. For the average user, some of the thirty-eight questions may raise or focus the user's attention on new issues for the first time-signaling that they are valid and important topics to consider during the election. Conversely, the exclusion of other 
topics (e.g., positions on same-sex marriage, abortion politics, door-to-door postal service, or military participation in Syria) fails to educate voters, and risks signaling a lower importance or relevance. Finally, fundamental questions about the role of the tool remain unclear. While the website aspires towards the neutral presentation of each party's positions, this is pragmatically difficult. Does presenting the party's position neutrally, for instance, involve highlighting important discrepancies between promises and actions, or simply regurgitating each party's stated position? Additionally, given there are three left-of-center parties, a significant clustering affect often arises within those scores (e.g., having all three parties score within $10 \%$ of each other). One approach would be to provide a logarithmic scale of sorts, allowing for more differentiation among similar parties. Another would be to consider error bars around the scores attained, to address the overreaching certainty in Figure 3.

\section{ISIDEW WTH.ò}

\section{News Quiz Polls Your Results}

\section{I side with Liberal on most political issues}

\section{Parties you side with...}

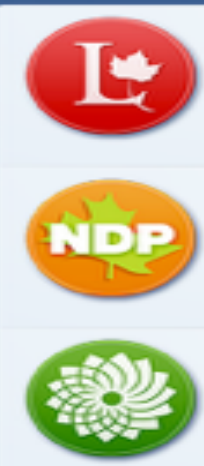

\section{Liberal}

on domestic pollicy, healthcare, economic, electoral, social,

education, and immigration iscues.

compare answers

\section{New Democratic}

on domestic pollicy, healthcare, economic, foreign policy, socisl,

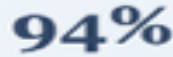

education, and immigration lissues.

compare answers

\section{Green}

on domestic policy, healthcare, foreign policy, economic, electoral, social, education, and immigration issues.

compare answers

Figure 3: An example of closely clustered scores and unclear margins of error 


\section{Should We Entrust Voter Education to Algorithms?}

Online quizzes as a tool for voter engagement and education trigger a host of complex questions about the ethics and implementation of an emerging technology. It would be easy, therefore, to react with generalized concern, hesitation, and opposition to their use. Yet, the questions they bring to the foreground-how to fairly and neutrally represent a party's position, how to deal with changing stances, or how to reveal hidden calculations and judgments-are not unique to digital mechanisms alone, but are present in all efforts at public communication, education, and engagement. In fact, the digital interface (and its popularity) affords a unique opportunity to examine these issues, offer improvements, and implement them in near real time.

The solution, therefore, isn't to fear or downplay the role of online quizzes or algorithms in the democratic process. In fact, there may even be value to incorporating them more directly, such as having voters complete such a quiz while in the polling booth to encourage them to weigh its results against their party predilections. Instead, we ought to bring these methodological challenges and questions to the foreground and urge sites like iSideWith to be more transparent and open about their decisions, designs, and algorithms. 